\title{
Anticoagulant, fibrinogenolytic and anti-platelet aggregation activities of Lablab purpureus (L.) Sweet seed radicle aqueous extract
}

\author{
Thoyajakshi R S \& Poornima D* \\ Department of Studies \& Research in Biotechnology, Tumkur University, Tumkur, India \\ *Email: samrudhpoornagirish@gmail.com
}

\section{ARTICLE HISTORY}

Received: 16 August 2020

Accepted: 06 October 2020

Published: 01 January 2021

\section{KEYWORDS}

LPRE; Protease; Anticoagulant;

Anti-platelet aggregation;

Fibrinogenolytic

\section{ABSTRACT}

The current study explores the anticoagulant, fibrinogenolytic and anti-platelet aggregation activities of Lablab purpureus (L.) Sweet seed radicle extract (LPRE). It is firstly reported that LPRE has protein at a concentration of $1.5 \mathrm{mg} / \mathrm{ml}$ and further evaluated for protein in gel electrophoresis. The proteolytic activity of LPRE was evaluated using casein and gelatin as substrate. LPRE showed a specific activity of $0.35 \mathrm{U}$. LPRE increased the plasma clotting time significantly showing its anticoagulant property. LPRE hydrolyzed the $A \alpha, B \beta$ and $\gamma$ chains of fibrinogen. Furthermore, LPRE significantly inhibited the platelet aggregation induced by agonist adenosine diphosphate (ADP).

\section{Introduction}

According to World Health Organization (WHO) cardiovascular disease (CVDs) remains a prominent cause of mortality from myocardial infarctions, strokes from usual blood clots $(1,2)$. About $31 \%$ of the global deaths are from CVDs, and about $85 \%$ of them are from stroke and heart attack. Overactivity of the coagulation cascade (hypercoagulation) increases the risk of thrombosis formation leading to thromboembolisms which in turn lead to ischemia by blocking blood flow and damaging the organs (3).

Blood coagulation has an intricate, highly controlled network of reactions involving coagulation factors which gets activated sequentially forming a blood clot. Unregulated blood clot formation leads to formation of thrombus (4). Thrombosis could lead to occlusion of blood vessels and should be treated with anti-coagulant drugs (5).

Thrombosis is treated with anticoagulants such as unfractionated heparin (UFH), coumarins, low molecular weight heparin (LMWH) and pentasaccahride fondaparinux (6). Even though the anticoagulants are efficient, the problem in their administration and the deleterious life-threatening side effects such as bleeding complications limit their usage (7). Since the anticoagulant drugs are expensive and have serious side effects, there is a need to explore alternative anticoagulants with more efficacy and less side effects.

Medicinal plants/plant extracts have been used in traditional Ayurvedic medicinal practitioners to prevent and/or treat various ailments (8). There are several medicinal plants reported to be having anticoagulant property and can serve as an alternative for current anticoagulant agents (9). Several studies have reported that dietary anticoagulants/ phytoconstituents could reduce the risks of thromboembolism $(10,11)$.

The Lablab purpureus (L.) Sweet belongs to the family Fabaceae. Different parts of the plant is used as anti-inflammatory, aphrodisiac, antispasmodic, antidiabetic, febrifuge, bilious, stomachic and phlegmatic disorders $(12,13)$. In addition, the plant decoction has been used in alcoholic intoxication to treat cholera, diarrhoea, gonorrhoea, leucorrhoea and in globefish poisoning. The seed pods juice was used to treat the digestive problems, expel worms and to treat inflamed throat and ears. The flowers are used to treat uterus inflammation and increase menstrual flow $(14,15)$.

\footnotetext{
(C) Thoyajakshi \& Poornima (2021). This is an open-access article distributed under the terms of the Creative Commons Attribution License, which permits unrestricted
} use, distribution and reproduction in any medium, provided the original author and source are credited (https://creativecommons.org/licenses/by/4.0/).

To cite this article: Thoyajakshi R S, Poornima D. Anticoagulant, fibrinogenolytic and anti-platelet aggregation activities of Lablab purpureus (L.) Sweet seed radicle aqueous extract. Plant Science Today. 2021;8(1):89-94. https://doi.org/10.14719/pst.2021.8.1.917 
In view of finding a natural dietary anticoagulant, this study we have investigated the in vitro anticoagulant, fibrinogenolytic and anti-platelet aggregation activities of Lablab purpureus (L.) Sweet seed radicle extract (LPRE).

\section{Materials and Methods}

\section{Sample collection and aqueous extract preparation}

Lablab purpureus (L.) Sweet seeds (round and matured) were procured from merchandise in Tumkur district $\left(13.3379^{\circ} \mathrm{N}, 77.1173^{\circ} \mathrm{E}\right)$, Karnataka state, India. L. purpureus (L.) Sweet plants were grown in Tumkur at temperature between $28-30{ }^{\circ} \mathrm{C}$ in high organic matter soil. The seeds were harvested during September - December months. The plant was identified by Prof. Sharanappa, Professor, Department of Biosciences, Hemagangotri, University of Mysore, Hassan. A herbarium specimen was maintained in Department of Studies and Research in Botany, Tumkur University, Tumkur (TUB-012).

Seeds (500 gm) were soaked in distilled water (11) for $48 \mathrm{hr}$. The soaked seeds were kept in a closed container for $48 \mathrm{hr}$ at $37{ }^{\circ} \mathrm{C}$ for sprouting. The sprouted seeds were collected. Sprout radicle was separated from cotyledon and dried in an incubator at $40{ }^{\circ} \mathrm{C}$ with humidity upto $70 \%$ for $48 \mathrm{hr}$. The dried sprout radicles were finely powdered using electrical grinder and stored at ${ }^{-} 20^{\circ} \mathrm{C}$ freezer (humidity about $95 \%)$ until further use. The radicle powder (10 gm) was suspended in distilled water $(100 \mathrm{ml})$ and kept on magnetic stirrer for $24 \mathrm{hr}$ at a speed of $400 \mathrm{rpm}$ to prepare aqueous extract. Later the extract was centrifuged at $10000 \mathrm{rpm}$ (Remi C-24BL centrifuge) and supernatant was collected. The supernatant was concentrated and named as Lablab purpureus (L.) Sweet seed radicle extract (LPRE). The LPRE stored at $-20{ }^{\circ} \mathrm{C}$ (humidity about $95 \%$ ) freezer until further use.

\section{Protease activity}

Protease activity was analysed (16) using casein (2\% in $200 \mathrm{mM}$ Tris-hydrochloric acid $(\mathrm{HCl})$ buffer, $\mathrm{pH}$ 8.0) as substrate. LPRE was incubated with $0.4 \mathrm{ml}$ of casein at $37{ }^{\circ} \mathrm{C}$ for $180 \mathrm{~min}$. Later, the reaction terminated by adding trichloroacetic acid and the sample centrifuged (3000 rpm for $5 \mathrm{~min}$ ). After centrifugation $1 \mathrm{ml}$ of supernatant was collected and sodium carbonate and diluted Folin-Ciocalteu reagents were added and kept at $37^{\circ} \mathrm{C}$ for $20 \mathrm{~min}$. The intensity of the colour developed was measured using Elico CL63 colorimeter at $660 \mathrm{~nm}$. Enzyme activity was stated as the enzyme required for an incremental increase of absorbance by 0.01 at 660 $\mathrm{nm}$ in $1 \mathrm{hr}$.

\section{Electrophoresis}

Sodium dodecyl sulphate polyacrylamide gel electrophoresis (SDS-PAGE) was carried out according to standard procedure (17). LPRE was loaded onto $10 \%$ gel and electrophoresis was carried out for $2 \mathrm{hr}$ at 90 Volts. Gel was stained with Coomassie brilliant blue R-250 (CBB) and visualized using Gel.LUMINAX gel documentation system.

\section{Zymography}

Casein/gelatin zymogram was carried out (17). The $10 \%$ gel incorporated with gelatin $(0.2 \%)$ as substrate used for zymogram assay. LPRE was incubated with sample buffer and electrophoresis was done. SDS was removed using Triton X-100 and gel was incubated in buffer (COMPOSITION) overnight. The gel was stained with CBB.

\section{Fibrinogenolytic activity}

Fibrinogenolytic activity was carried out (18). Human fibrinogen $(50 \mu \mathrm{g})$ incubated for $2.5 \mathrm{~h}$ at $37{ }^{\circ} \mathrm{C}$ with different concentrations of LPRE in sodium phosphate buffer. After incubation reducing sample buffer was added and we analyzed the hydrolyzed products in $12 \%$ SDS-PAGE.

\section{Coagulation assays}

\section{Recalcification time (RT)}

The RT was determined following standard procedure (19). Citrated human plasma $(100 \mu \mathrm{l})$ was incubated with LPRE ( $3-18 \mu \mathrm{g}$ ) at $37^{\circ} \mathrm{C}$ for $15 \mathrm{~min}$. After incubation, $100 \mu \mathrm{l}$ of $25 \mathrm{mM} \mathrm{CaCl}_{2}$ was added and time taken for visible clot formation was recorded.

\section{Prothrombin time (PT)}

PT was determined as per standard procedure (20). $100 \mu \mathrm{l}$ of plasma was incubated with different concentrations of LPRE $(6-36 \mu \mathrm{g})$ at $37{ }^{\circ} \mathrm{C}$ for $15 \mathrm{~min}$. After incubation, $0.2 \mathrm{ml}$ of liquid calcified thromboplastin (Uniplastin reagent from Tulip Diagnostics Pvt. Ltd., Goa) was added and time taken for clot formation was recorded.

\section{Activated partial thromboplastin time (aPTT)}

APTT kit was procured from Tulip Diagnostics Pvt. Lt. Goa. The assay was performed as described in the manufacturer's protocol. Citrated human plasma (100 $\mu \mathrm{l})$ was incubated with LPRE $(6-30 \mu \mathrm{g})$ at $37^{\circ} \mathrm{C}$ for 5 min. After incubation $100 \mu \mathrm{l}$ of Liquicelin-E was added and kept for 5 minutes. $100 \mu$ of $\mathrm{CaCl}_{2}$ was added and time for visible clot formation was recorded.

\section{Platelet aggregation}

Platelet aggregation was analysed in Chrono-Log Model 700-2D aggregometer (ChronoLog Corp., USA). We collected blood from healthy volunteers. Platelet-rich plasma (PRP) was obtained by centrifuging human blood $(1: 9 \mathrm{v} / \mathrm{v}$ in $3.2 \%$ trisodium citrate) at $900 \mathrm{rpm}$ for $15 \mathrm{~min}$; the resultant supernatant was PRP. The blood sample was centrifuged at $3000 \mathrm{rpm}$ for $20 \mathrm{~min}$ to obtain Platelet Poor Plasma (PPP) as the supernatant. 250 $\mu$ l of PRP was taken in siliconized glass cuvette with stir bar stirring at $1200 \mathrm{rpm}$. The platelet aggregation was initiated by adding ADP $(10 \mu \mathrm{m})$. Different concentration of LPRE incubated with PRP for $15 \mathrm{~min}$ and aggregation were initiated by adding ADP. The aggregation was monitored for 6 minutes by change in turbidity with PRP and PPP representing $0 \%$ and $100 \%$ transmittance respectively. 


\section{Protein estimation}

Protein concentration was estimated (21) and BSA is used as standard.

\section{Statistical analysis}

Results were represented as mean \pm standard error. One-way analysis of variance was used for statistical significance of intergroup differences and the Tukey test was used for comparison of means. The Statistical Package for Social Sciences (SPSS) version 15.0 (SPSS Inc., Chicago, IL, USA) was used to perform all analysis.

\section{Results and Discussion}

The Lablab purpureus (L.) Sweet seed radicle extract (LPRE) has a protein concentration of $1.5 \mathrm{mg} / \mathrm{ml}$. Analysis of LPRE by SDS-PAGE showed protein bands distributed majorly in medium molecular weight region (Fig. 1). LPRE showed a proteolytic activity of $0.35 \mathrm{U}$. In zymogram study (using casein and gelatin

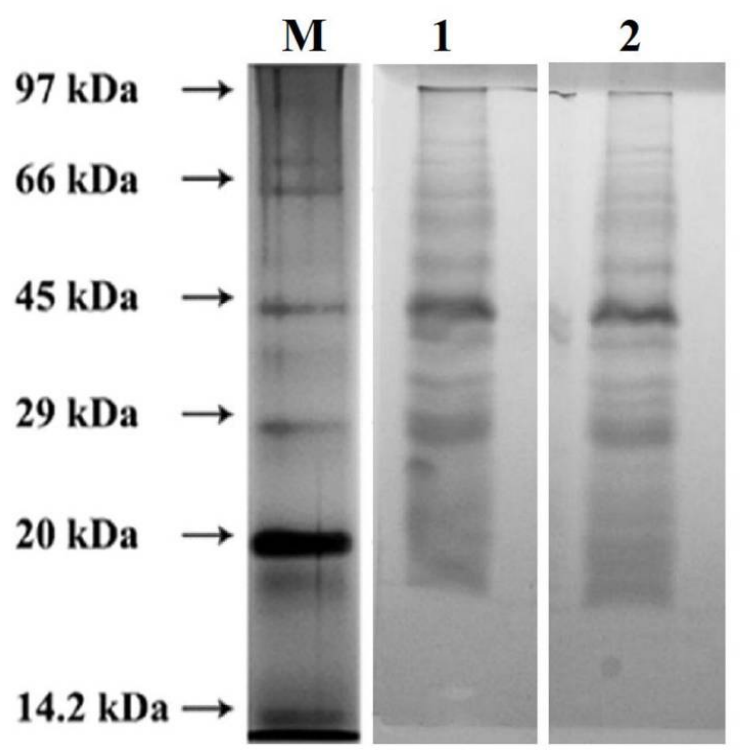

Fig.1. Electrophoresis. LPRE (120 $\mu \mathrm{g})$ was loaded on to the $10 \%$ SDS-PAGE in non-reducing and reduced conditions. Lane $\mathrm{M}$ : molecular weight markers, lane 1: LPRE $(120 \mu \mathrm{g})$ in non-reducing condition, lane 2: LPRE $(120 \mu \mathrm{g})$ in reducing condition.

as substrate) LPRE showed translucent activity bands, confirming protease (Fig. 2). Proteases from seeds have broad specificity. They can hydrolyse casein, gelatin and extracellular matrix $(22,23)$.

Blood coagulation is a complex physiological process that drives immediate response to blood vessel injury. Impairment in coagulation process leads to the hyper-activation of the coagulation factors, which results in thrombotic disorders (4). Thrombosis results in formation of unusual clot in the arteries and veins increasing cerebrovascular/cardiovascular complications (6). Currently available antithrombotic agents have lifethreatening side effects. Anticoagulants from the natural sources are preferable for curing thrombotic disorders. Several anticoagulant agents from natural sources of plant/seed extracts have reported and

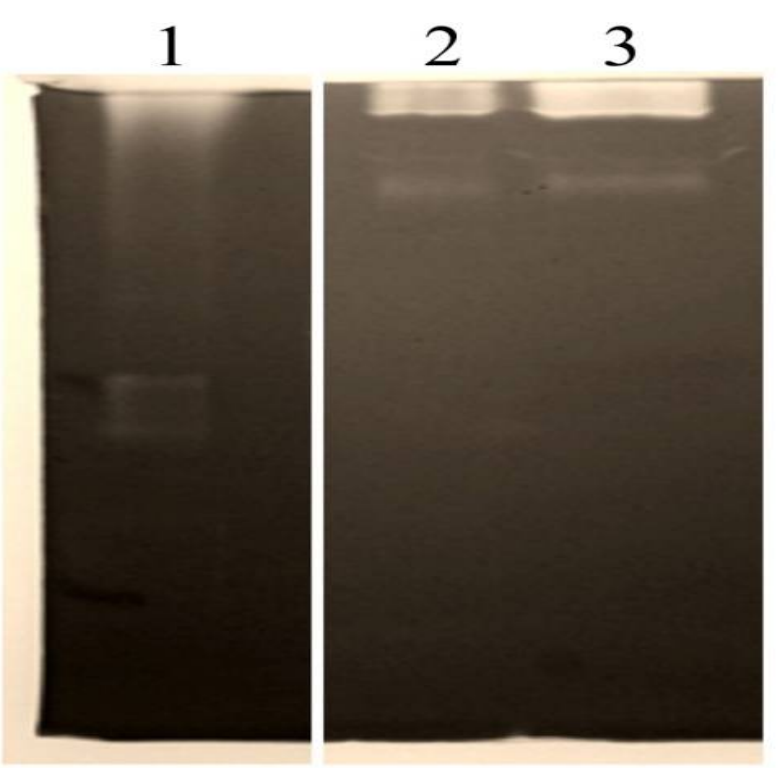

A
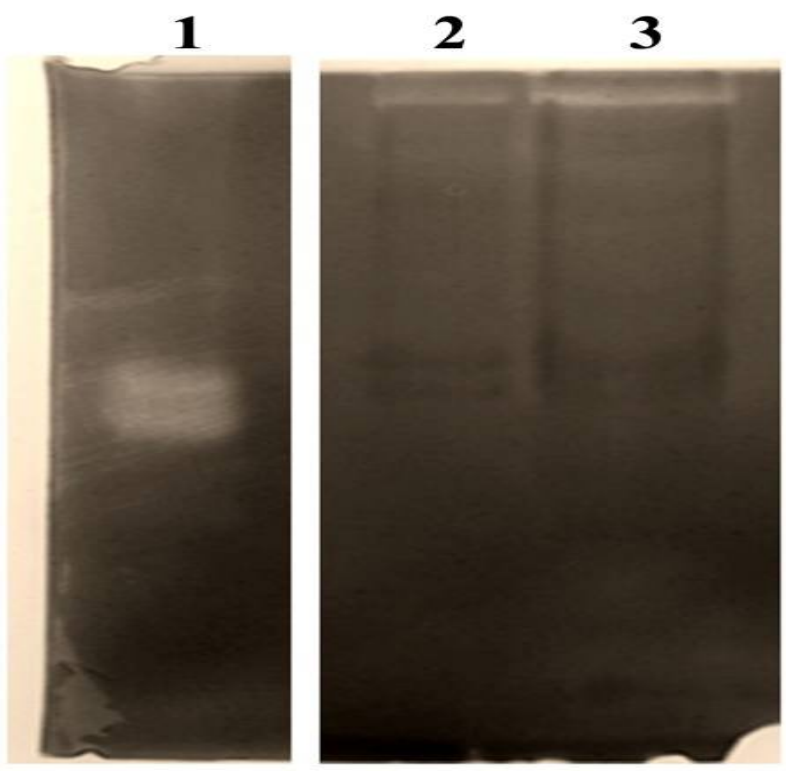

B

Fig. 2. Zymogram assay. The LPRE was loaded onto SDS-PAGE copolymerized with gelatin (A) or casein (B) for the detection of proteolytic activity. After electrophoresis, SDS was removed by using Triton X-100. Later incubated overnight in incubation buffer and stained with CBBR-250. Lane 1: Trypsin (5 $\mu \mathrm{g}) 2$ and 3: LPRE $50 \mu \mathrm{g}$ and $100 \mu \mathrm{g}$.

these could be a better therapeutic candidate to treat thrombosis. The seed extract of Momordica charantia, Artocarpus heterophyllus, Pisum sativum, Macrotyloma uniflorum and Linum usitatissimum seeds found to show anticoagulant and anti-platelet aggregation effects $(22,23,25)$.

LPRE showed significant anticoagulant activity. Upon incubation with plasma, LPRE increased the clotting time in RT from control $200 \mathrm{sec}$ to $700 \mathrm{sec}$ with $18 \mu \mathrm{g}$ (Fig. 3A), in PT from control $16 \mathrm{sec}$ to 700 sec with $36 \mu \mathrm{g}$ (Fig. 3B) and in APTT from control 36 sec to 665 sec with $30 \mu \mathrm{g}$ (Fig. 3C) concentration. In RT calcium activates the common pathway of blood coagulation. Calcium along with phospholipid and 


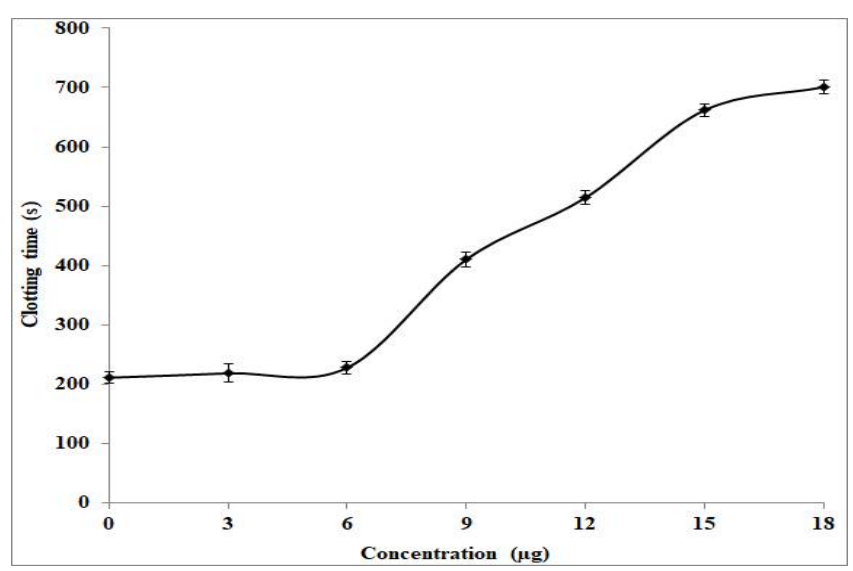

A

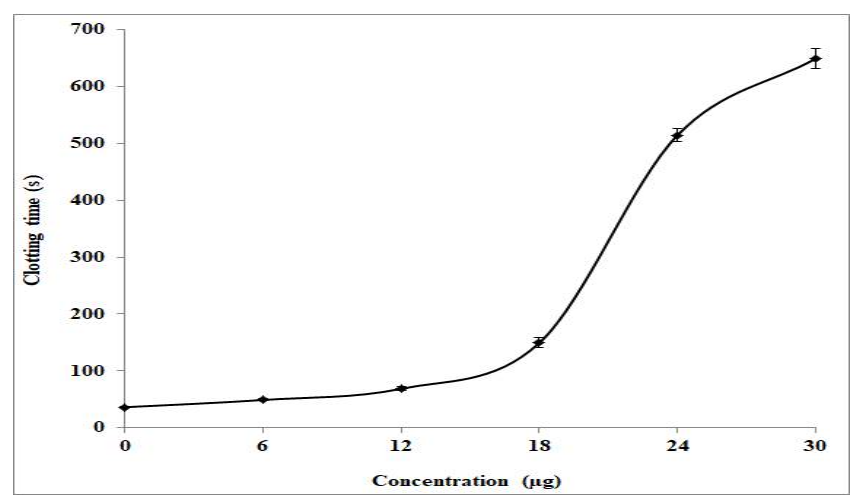

B

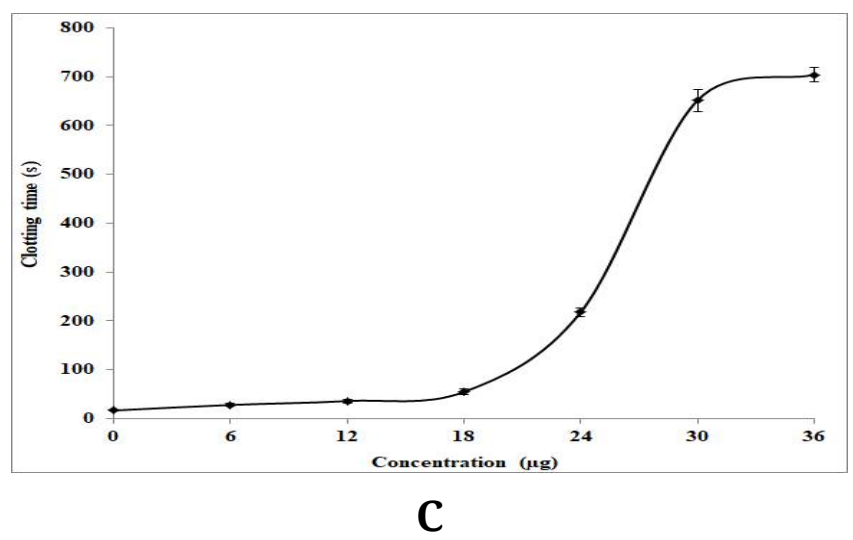

Fig. 3. Coagulation studies. A. Recalcification time. Different concentration of LPRE (3 - $18 \mu \mathrm{g})$ was incubated with human plasma $(100 \mu \mathrm{l})$ for $5 \mathrm{~min}$. After incubation, $100 \mu \mathrm{l}$ of $\mathrm{CaCl}_{2}$ was added and time taken for visible clot formation was recorded. B. Activated partial thromboplastin time (aPTT). Different concentration of the LPRE (6 - $30 \mu \mathrm{g})$ was incubated with $100 \mu \mathrm{l}$ of plasma for $10 \mathrm{~min}$ and after incubation $100 \mu \mathrm{l}$ of liquicelin-E was added and again incubated for $5 \mathrm{~min}$. To this mixture $100 \mu \mathrm{l}$ of $\mathrm{CaCl}_{2}$ was added and time taken for visible clot formation was recorded. C. Prothrombin time (PT). Different concentration of LPRE (6 - $36 \mu \mathrm{g})$ was incubated with $100 \mu \mathrm{l}$ of plasma for $10 \mathrm{~min}$ and after incubation $200 \mu \mathrm{l}$ of uniplastin was added, the clotting time was recorded. All the values are presented as mean \pm standard error of the mean $(n=5)$.

factor V activates factor II. PT was evaluated using uniplastin reagent containing ready to use liquid calcified thromboplastin reagent. Thromplastin in presence of calcium activates the extrinsic pathway of human blood coagulation. While APTT was evaluated using liquicelin-E reagent containing phospholipid with ellagic acid as an activator. Cephaloplastin activates the coagulation factors of intrinsic pathway of coagulation mechanism in the presence of calcium. This suggests that LPRE interfere in intrinsic, extrinsic and in common pathway of coagulation cascade. The protease(s) present in the LPRE sample might be responsible for the anticoagulant property exhibited (22).

We evaluated the fibrinogenolytic activity for LPRE. The LPRE hydrolysed all the chains of fibrinogen ( $A a, B \beta$ and $\gamma$ ) at a concentration of $3 \mu \mathrm{g}$ in a dose dependent manner (Fig. 4). Generally, proteases which degrade fibrinogen from its Cterminal end generate truncated fibrinopeptides

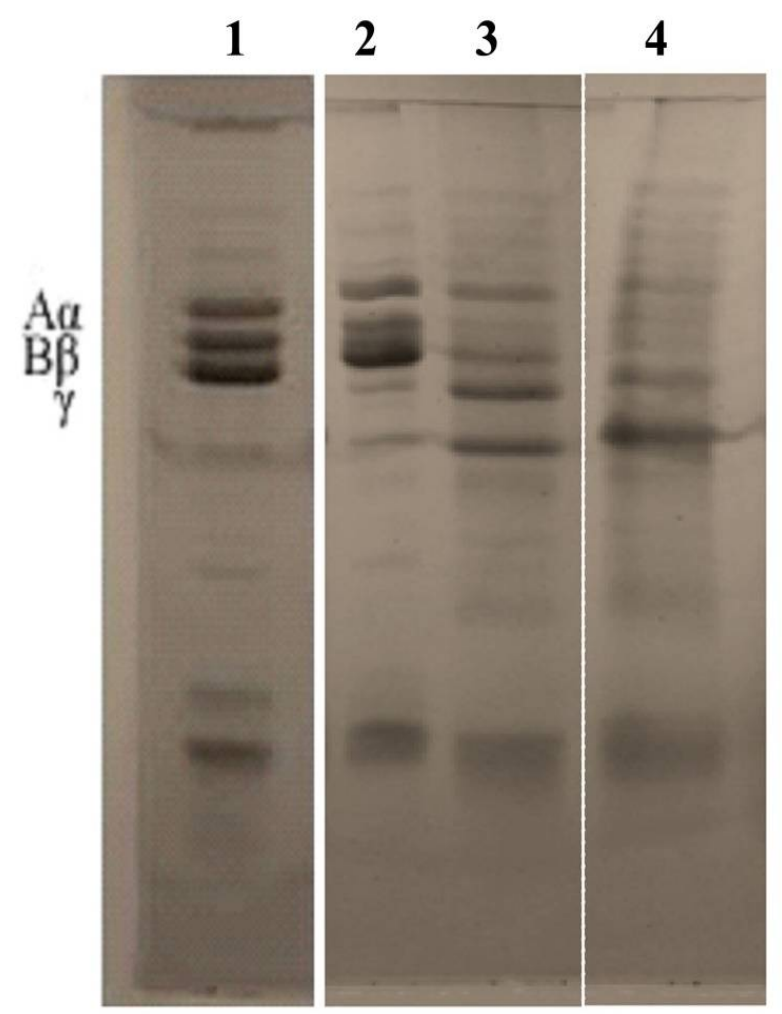

Fig. 4. Fibrinogenolytic activity. Human fibrinogen $(50 \mu \mathrm{g})$ was incubated with LPRE $(0.06 \mu \mathrm{g}, 0.3 \mu \mathrm{g}$ and $3 \mu \mathrm{g})$ at $37^{\circ} \mathrm{C}$ for $2.5 \mathrm{~h}$. SDS-PAGE performed under reducing condition. Lane 1: fibrinogen (50 $\mu \mathrm{g}$ ), lane 2 - 4: fibrinogen incubated with $0.06 \mu \mathrm{g}, 0.3 \mu \mathrm{g}$ and 3 $\mu \mathrm{g}$ of LPRE respectively.

exhibiting anti-coagulant activity. Similar fibrinogenolytic activity has been reported from Tridax procumbens, Jatropha curcas and Plumeria alba (23 - 25).

Platelets are anuclear discoid-shaped cells originating from stem cells of bone marrow megakaryocytes which play an important role in blood coagulation (26). The platelets aggregate to form platelet plug at the site of injury, along with fibrin clot to form blood clot. During thrombotic disorder, platelets also contribute for the formation of an unusual clot in blood vessels. LPRE significantly inhibited the ADP-induced platelet aggregation to an extent of $80 \%$ at the concentration of $100 \mu \mathrm{g}$ (Fig. 5A and B). The factors that act as antiplatelet aggregating agents play a key role in inhibiting unusual blood clots. Several antiplatelet agents have been reported from snake, microbes, plants and animal sources $(24,27)$. 


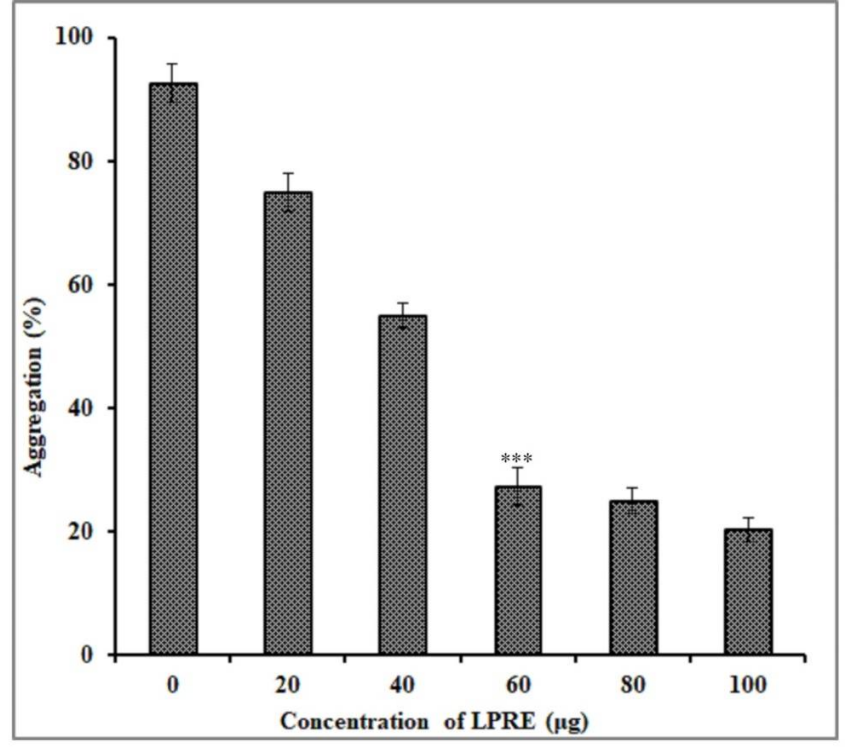

A

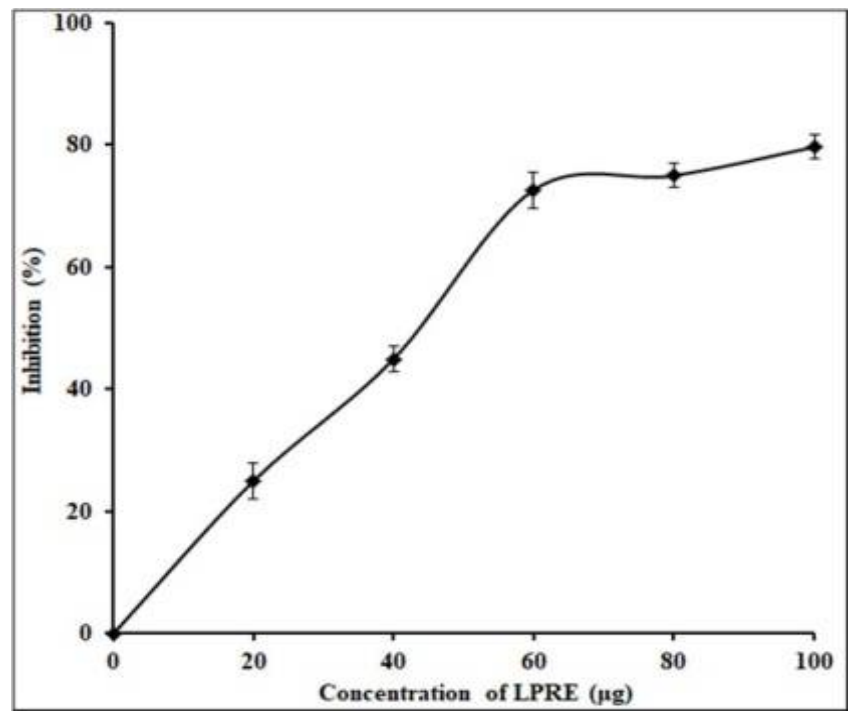

B

Fig. 5. Platelet-aggregation. Aggregation of platelet was monitored in a Chrono-Log Model 700 aggregometer. Platelet-rich plasma $(0.25 \mathrm{ml})$ was incubated with LPRE for $15 \mathrm{~min}$ and later aggregation was initiated by adding $\operatorname{ADP}(10 \mu \mathrm{m})$. The reaction mixtures were monitored for platelet aggregation. All the values are presented as mean \pm standard error of the mean $(n=5)$. (A) The percentage of platelet aggregation with LPRE; (B) The percentage of inhibition of platelet aggregation by LPRE. All the values are presented as mean \pm standard error of the mean $(n=5)$. Statistically significant results are indicated by asteriks *** $-\mathrm{p}<0.001$.

\section{Conclusion}

The present study for the first time demonstrates that Lablab purpureus (L.) Sweet seed radicle extract (LPRE) has proteolytic activity associated with fibrinogenolytic activity which exhibit anticoagulant and anti-platelet aggregation effect. The findings give an opportunity for isolation of bioactive molecule from LPRE with potent anticoagulant property which can be further used in clinical applications.

\section{Acknowledgements}

The authors thank Dr. S. Nagaraju for helping in conducting the coagulation studies.

\section{Authors' contributions}

TRS collected the specimen, prepared the LPR extract and conducted the experiments. TRS and PD contributed in the preparing and editing the complete manuscript. Both the authors have read and approved the manuscript.

\section{Conflict of interests}

The authors declare that there is no competing interest.

\section{Ethical issues}

The present study was according to Ethical guidelines approved through the Ethical Committee of Faculty of Pharmacy, Sree Siddaganga College of Pharmacy (Reference Number: SSCPT. Clear/152/2016-17).

\section{References}

1. Roth GA, Johnson C, Abajobir A, Abd-Allah F, Abera SF, Abyu G. Global regional and national burden of cardiovascular diseases for 10 causes, 1990 to 2015. J Am College Cardiol. 2017 70(1): 1-25. https://doi.org/10.1016/j.jacc.2017.04.052

2. Gaziano TA, Bitton A, Anand S, Abrahams-Gessel S, Murphy A. Growing epidemic of coronary heart disease in low- and middle-income countries. Curr Probl Cardiol. 2010; 35:72-115. https://dx.doi.org/10.1016\%2Fj.cpcardiol.2009.10.002

3. Previtali E, Bucciarelli P, Passamonti SM, Martinelli I. Risk factors for venous and arterial thrombosis. Blood Transfus. 2011; 9(2):120-38. https://dx.doi.org/10.2450\%2F2010.0066-10

4. Ovanesov MV. Study of the regulation of blood coagulation by factors VIIa and IXa. U.S Food \& Drug Aministration, Biologic research project, New Hampshire Avenue, Silver Spring, MD. 2015.

5. Karch AM. Pharmacologial review: Drugs that alter blood coagulation. Am Nurse Today. 2012;7(11):26-31.

6. Aguirre J, Borgeat A. Drugs for Thromboprophylaxis: Unfractionated heparin, low molecular weight heparin, warfarin and fondaparinux. In: LLAU JV. Editor. Thromboembolism in Orthopedic Surgery, London: Springer, London, England. 2013;53-65.

7. Kumar S, Joseph L, George M, Sharma A. A review on anticoagulant / antithrombotic activity of natural plants used in traditional medicine. Int J Pharm Sci Rev Res. 2011;8:70-74.

8. Newman DJ, Cragg GM. Natural products as sources of new drugs over the 30 years from 1981 to 2010. J Nat Prod. 2012; 75:311-35. https://doi.org/10.1021/np200906s

9. Akram M, Rashid A. Anti-coagulant activity of plants: mini review. J Thromb Thrombolysis. 2017;44:406-11. https://doi.org/10.1007/s11239-017-1546-5

10. Lee W, Yang EJ, Ku SK, Song KS, Bae JS. Anticoagulant activities of oleanolic acid via inhibition of tissue factor expressions. The Korean Society for Biochemistry and $\begin{array}{lll}\text { Molecular } & \text { Biology. } & \text { 2012:45(7):390-95. }\end{array}$ https://doi.org/10.5483/bmbrep.2012.45.7.065

11. Manicam C, Abdullah JO, Tohit ERM, Seman Z, Chin SC, Hamid $\mathrm{M}$. In vitro anticoagulant activities of Melastoma malabathricum Linn. aqueous leaf extract: A preliminary novel finding. J Med Pla Res. 2010; 4(14): 1464-72. https://doi.org/10.5897/JMPR10.136

12. Sheila MK, Anselimo OM, Glaston MK. Physical characteristics, proximate composition and anti-nutritional factors in grains of lablab bean (Lablab purpureus (L.) Sweet) genotypes from Kenya. J App Bio. 2017; 114:11289-98. https://dx.doi.org/10.4314/jab.v114i1.2 
13. Dilara P, Mir Muhammad NU, Siddiqu MI, Salma P, Mohammad S. Phytochemical screenings, thrombolytic activity and antimicrobial properties of the leaf extracts of Lablab purpureus. Am J Res Com. 2013;1(2):49-55.

14. Bhogireddy N, Vamsi Krishna AN, Ramesh B, Pradeep K, Reddy OVS, Gaddaguti V, Raj Kumar K, Pola PK, Venkataraman B. Anti-inflammatory and anti-diabetic activities with their other ethnomedicinal properties of the plants. J Med Pla Stu. 2013;1(5):87-96

15. Kante K, Reddy CS. Anti diabetic activity of Dolichos lablab (seeds) in streptozotocin-nicotinamide induced diabetic rats. Hyg J Dru Med. 2013;(1):32-40.

16. Satake K, Okuyama T, Ohashi M, Shinoda T. The spectrophotometric determination of amine, amino acid and peptide with 2,4,6-trinitrobenzene1-sulfonic acid. J Biochem. 1960; 47:654-60. https://doi.org/10.1093/oxfordjournals.jbchem.a127107

17. Laemmli UK. Cleavage of structural proteins during the assembly of the head of bacteriophage T4. Nature 1970; 227:680-85. https://doi.org/10.1038/227680a0

18. Nagaraju S, Kempaiah K. 'Partitagin', a unique $\beta, \gamma$ fibrinogenase that inhibits platelet aggregation from Hippasa partita spider venom. Blood Coagul Fibrino. 2011;22:24-28. https://doi.org/10.1097/mbc.0b013e32833fcc15

19. Condrea E, Yang CC, Rosenberg P. Anticoagulant activity and plasma phosphatidylserine hydrolysis by snake venom phospholipases A2. Thromb Haemost. 1983;49:151.

20. Quick AJ. Stanley-Brown M, Bancroft FW. A study of the coagulation defect in hemophilia and in jaundice. Am J Med Sci. 1935;190:501-11. http://doi.org/10.1055/s-0038-1650068

21. Lowry $\mathrm{OH}$, Rosebrough NJ, Farr AL, Randall RJ. Protein measurement with the Folin-phenol reagent. J Biol Chem.
1951;193:265-75.

22. Rawski RI, Sanecki PT, Dżugan M, Kijowska K. The evidence of proteases in sprouted seeds and their application for animal protein digestion. Chem Zvesti. 2018; 72 (5): 1213-21. http://dor.org/10.1007/s11696-017-0341-2

23. Vinod G, Kusuma CG, Bhavana S, Sumachirayu CK, Nagaraju S. Anti-hemostatic protease from Jatropha curcas latex with fibrinogen lytic activity. J Pharmacogn Phytochem. 2019b; 8(1):1303-10.

24. Vinod G, Kusuma CG, Bhavana S, Sumachirayu CK, Ravikumar $\mathrm{H}$, Nagaraju S. Potent procoagulant and platelet aggregation inducing serine protease from Tridax procumbens extract. Pharmacognosy Res. 2019c;11(4):363-70. http://doi.org/10.4103/ pr.pr-4-19

25. Vinod G, Nagaraju S. Ethnomedicinal, phytochemical constituents and pharmacological activities of Tridax procumbens: a review. Int J Phar Pharm Sci. 2016;8(2):1-7.

26. Drake TA, Morrissey JH, Edgington TS. Selective cellular expression of tissue factor in human tissues. Implications for disorders of hemostasis and thrombosis. Ame J Pathol. 1989;134:1087-97.

27. Rachidi S, Aldin ES, Greenberg C, Sachs B, Streiff M, Zeidan AM. The use of novel oral anticoagulants for thromboprophylaxis after elective major orthopedic surgery. Exp Rev Hematol. 2013;6:677-95. https://dx.doi.org/10.1586\%2F17474086.2013.853430

28. Zare H, Moosavi, Movahedi AA, Salami M, Mirzaei M, Saboury AA Sheibani N. Purification and autolysis of the ficin isoforms from fig (Ficus carica cv. Sabz) latex. Phytochemistry. 2013;87:16-22. https://dx.doi.org/10.1016\%2Fj.phytochem.2012.12.006 